\title{
O VIDEODOEMA COMO performance: movimento e corporeidade virtual da palavra
}

Luciano Rodrigues Lima

Nota prévia

A recepção deste artigo seria mais proveitosa se feita através da leitura em tela do computador conectado à internet. Em razão disto é que a exemplificação se dá através dos sites de videopoema, cujos endereços encontram-se no texto. Desse modo, clicando nos endereços, o leitor acessará facilmente os videopoemas indicados, os quais não se prestam a outro tipo de demonstração, a não ser através da sua própria performance em tela, onde se encontram os recursos multimídia que dão vida a esse tipo de arte digital.

Aspectos políticos e estéticos dos corpos e espaços virtuais

Stephen Wilson, no seu livro Information Arts: Intersections of Art, Science, and Technology (Artes da informação: interseçōes da arte, ciência e tecnologia, tradução nossa), um tratado de 945 páginas, ainda não traduzido para o português, dedica uma parte do livro à natureza da experiência virtual. Seus interlocutores, aí, são pensadores e críticos da tecnologia virtual como Marcos Novak, N. Katherine Hayles, Francis Dyson, Simon Penny, Hakim Bey (autor de The Information War, A guerra da informação), Arthur e Marilouise Kroker (autores de Code Warriors, Guerreiros do código), dentre outros. 
Para Wilson, a ênfase na descorporificação e no ciberespaço podem ser vistas como manifestaçóes de narrativas políticas. (Wilson, 2002, p. 635) Isto pode significar a emergência de uma nova "classe virtual" (termo usado por Arthur e Marilouise Kroker, em Code Warriors) de pessoas, as quais usam a fascinação do mundo cibernético para desacreditar a experiência sensorial independente e facilitar o caminho para a dominação. Este processo dar-se-ia através do privilégio à informação e do extermínio do significado. Como resultado desse processo alienante, o espaço físico das cidades também se torna uma prisão. As cidades podem ser vistas, então, como espaços fechados reservados à comunicação de dados.

Alguns, como Hakim Bey, citado por Wilson, veem ainda a mídia digital como a serviço das religiōes, isto é, enquanto instituiçóes interessadas na desmaterialização da informação, no sentido de associar e redefinir o "espírito" como esse tipo imaterial de informação.

Cito como exemplo dessa fascinação pela imagem cibernética, no Brasil, os comerciais de grandes corporaçóes, como o Banco do Brasil, Petrobras e a Caixa Econômica. Mesmo sendo instituiçôes de capital majoritariamente estatal, isto é, pertencentes aos cidadãos brasileiros, elas investem maciçamente em comerciais altamente tecnológicos e massificantes, os quais soam como uma forma de intimidação e demonstração ostensiva de poder. Essas instituiçôes, embora de caráter jurídico estatal (um conceito ligado ao caráter de instituição pública), atuam totalmente dentro da lógica competitiva de mercado, no mundo capitalista globalizado. Recentemente, um comercial dos combustíveis Petrobrás (ano 2007, exibido nos canais de TV por assinatura) mostrava uma pessoa distraída atravessando uma pista de testes e sendo surpreendida e eliminada (por um truque digital) pelo carro de corridas em velocidade vertiginosa. A morte e o apagamento da imagem da pessoa que atravessava a pista em um ritmo humano distraído não mostra sangue, gemidos ou agonia. É uma morte limpa, rapidíssima. A figura humana é simplesmente "deletada" da tela pelo carro de corrida. A cena do comercial pode fazer o espectador pensar: "Então é isto que acontece a quem não se enquadrar nesse novo mundo tecnológico avançado" (Algo como Seu Ribeiro, personagem de Graciliano Ramos, um típico autodidata de cidades pequenas do interior, o sábio do lugar, que teve suas pernas simbolicamente esmagadas pelas rodas do progresso). Seria um processo semelhante (embora sem as mesmas consequências imediatas) aos soldados americanos atirando e eliminando civis e suspeitos no Iraque, a partir de uma tela digital, com mira a laser e infravermelho, dentro de seus tanques e aviōes fechados e com ar-condicionado, enquanto ouvem rock pesado a toda altura (como na cena do documentário Farenheit 9/11, de Michael Moore). 
Talvez a tecnologia digital já esteja sendo utilizada como uma nova forma de poder político (com suas implicaçóes militares, econômicas, ideológicas etc.) mais cruel, fria e avassaladora do que qualquer outra invenção humana anterior.

Arthur e Marilouise Kroker ressaltam ainda as relaçôes políticas da realidade virtual, que denominam de utopia virtual, com as categorias de gênero e classe social, no contexto do capitalismo internacional, com o apoio de visionários digitais. Denunciam as atrocidades que estão sendo cometidas contra o espírito humano, em nome da evolução das mediaçôes digitais, que definem como:

.... virtual war strategy where knowledge is reduced to data storage dumps, friendship is dissolved into floating cyber interactions, and communication means the end of meaning. Virtualization in the cyber hands of the new technological class is all about our being dumbed down. (Kroker and Kroker, 1997, p. 56)

(...uma guerra virtual estratégica onde o conhecimento é reduzido à estocagem de dados sem critérios, a amizade é dissolvida em interações cibernéticas flutuantes e a comunicação significa o fim do significado. A virtualização nas mãos cibernéticas da nova classe tecnológica tem tudo a ver com a nossa imbecilização.) (tradução nossa)

A libertação do corpo e espaço pelo virtual, entretanto, pode ser vista, por outros, de modo menos pessimista. Para esses, como Florian Rotzer e Catherine Richards, através do virtual pode-se: desafiar a gravidade e o tempo, explorar as fantasias de forma impossível no plano biológico e material, libertar as mentes da prisão cartesiana, encontrar pessoas de modo sem precedentes, transformar identidades de modos diversos, remover as tradicionais fronteiras do ego, através de uma nova experiência imaginativa. Para Catherine Richards, observadora ligada à perspectiva feminista, a realidade virtual pode ajudar a redefinir o dualismo modernista típico mente/corpo, ao inventar novas imagens do corpo e proporcionar novos campos de intensidades, o que ajudaria na reconstrução da subjetividade feminina.

Porém, tanto os críticos pessimistas quanto os otimistas concordam em um ponto: a realidade virtual não é uma réplica da realidade material, mas uma possibilidade de problematizarmos e repensarmos todas as nossas relaçóes com o reino do simbólico e com aqueles tradicionais conceitos binários como mente/corpo, sujeito/objeto, material/imaterial. Ninguém, contudo, poderá esquecer os riscos de uma adesão alienada à realidade virtual (táo poderosa e arriscada, ou mais, do que a realidade material), esquecendo-se dos jogos de poder e dos processos inescrupulosos na manipulação dessas novas linguagens e tecnologias. 


\section{Poesia e performance}

Fazer poesia, hoje, pode significar muito mais do que escrever poemas em folhas de papel. O poeta-rapper, no hip-hop, recitará o seu texto em uma performance integrada por música, dança, efeitos especiais, em um palco de qualquer natureza (Esta condição do poeta não é nova: os trovadores medievais já praticavam e os cantadores nordestinos praticam uma poesia performática). $\mathrm{O}$ videopoeta recriará seu texto com os recursos digitais do computador e será seu próprio editor e distribuidor (desempenhando os papéis de editora e distribuidora/livraria), pois lançará o seu trabalho na rede, o qual será exposto em uma grande livraria/vitrine eletrônica. O rapper interage com a sua plateia e o videopoeta com os seus leitores virtuais, através da comunicação eletrônica. Ambos os poetas agregarão a seu trabalho elementos do espetáculo, do show, da performance, isto é, elementos da corporeidade.

\section{A arte do tempo e das realidades múltiplas}

Diana Domingues é uma artista contemporânea que possui um site de videoarte, onde exibe suas obras radicais, como instalaçóes virtuais baseadas em radiografias e imagens de outros tipos de scanners de uso médico. Ali, a artista póe texto sobre essa viagem ao interior do corpo, em uma proposta que busca unir poesia e ciência. O endereço do site é: <http://www.arte.unb.br/netlung/diana/diana2.htm>. (Essas técnicas construtivas que misturam tecnologia e poesia são recorrentes, na atualidade. $\mathrm{O}$ poeta pós-moderno norte-americano Charles Bernstein construiu o seu poema "I and the" [Eu e o] simplesmente a partir de uma lista de palavras, compiladas por um pesquisador em ordem decrescente de frequência de uso, de um banco de dados digitalizado contendo transcriçôes de 225 sessôes reais de psicanálise.)

Diana Domingues é também pesquisadora e publicou, como organizadora, dois importantes volumes sobre arte virtual e suas diversas implicações: $A$ arte no século XXI: a humanização das tecnologias (Editora da UNESP, 1997). Em 2003, ela voltou a assinar, como organizadora, ainda pela Editora da UNESP, outra importante publicação sobre temática semelhante, sob o título de Arte e vida no século XXI: tecnologia, ciência e criatividade. Em ambos os trabalhos comparecem autores nacionais e estrangeiros, traduzidos por Flávia Gisele Sarreta e Gilse Boscato Muratore. Os dois volumes constituem-se em valiosa fonte de pesquisa sobre arte contemporânea, principalmente em relação às propostas artísticas associadas às novas tecnologias. 
Em Arte e vida no século XXI: tecnologia, ciência e criatividade, Louise Poissant assina um interessante artigo, intitulado "Ser e fazer sobre a tela", traduzido por Gilse Boscato Muratore e Diana Domingues. Nesse artigo Poissant discorre sobre as artes da mídia e a posição do artista midiático:

No contexto tecnológico, contudo, somos ao mesmo tempo ator, ou melhor, ator-autor e espectador. A aparição torna-se um modo de ser com seus atributos de ubiquidade e de teletransporte que permitem agir, atar laços, experimentar papéis e, mais recentemente, assumir identidades em novos territórios com outras maneiras de existir. (Poissant, 2003, p. 120-1)

Fala, também, sobre a lógica da net:

A lógica da net, assim como a lógica da multimídia operam um deslocamento dos nomes para os verbos, como assinala Kevin Kelly (1995, p. 27), o que é bastante revelador das questóes e modalidades das redes e da multimídia em geral. Para existir numa vila e numa cidade é preciso instalar-se aí, ter uma casa, bens. Na rede, é preciso intervir. É preciso manifestar-se, criar laços, ligar e ligar-se novamente. Daí a importância das interfaces que vão determinar em grande parte as modalidades de conexão, o lugar concedido às diversas faculdades e aos sentidos, o tratamento do espaço e as novas formas de temporalidade (tempo real, tempo abstrato, ucronia etc). No registro do aparecimento, um novo espaço-tempo torna-se um presente-universal ou um nãolugar presente, como o diz tão bem Mário Costa (1988). (Poissant, 2003, p. 120)

Segundo Poissant, a arte midiática faz o ser humano livrar-se do biocentrismo, assim como, no passado, livramo-nos do geocentrismo através do telescópio e do antropocentrismo através do microscópio. Finalmente, admitimos não haver fronteiras entre o natural e o artificial, entre o homem e a máquina. Sobre isto Félix Guattari, em Caosmose, traz o conceito de "subjetividades maquínicas". O que distingue o pensamento de Guattari do de Poissant é o nível de otimismo com respeito às relaçóes homemtecnologia, alto nesta última e baixíssimo no primeiro.

Citanto Roy Ascott, que define a arte midiática como arte do aparecimento, em oposição à arte tradicional, que seria a arte da aparência, Poissant comenta especificamente as características performáticas das artes midiáticas:

As performances telemáticas convidam mais ao manifestar-se, ao estar presente, trazendo a contribuiçấo a um projeto coletivo. A arte das redes favorece o aparecimento e a disponibilidade de participar em um projeto com várias cabeças pensantes mais do que se voltar novamente a problemas ligados à tradição da aparência das formas na qual as 
representações são postas em circulação. E, se ainda houver representações, principalmente pelo recorte de avatares ou de cenários servindo de ambientes virtuais, essas representaçôes testemunham o savoir faire do interesse de seu autor, sendo que o participante remete um pouco ao que se fazia no autorretrato na época em que os pintores se serviam dele como portfólio junto a um mecenas. (Poissant, 2003, p. 120)

\section{$\mathrm{O}$ videopoema e a arte como performance}

Como toda produção veiculada pela internet, os videopoemas não são produzidos, necessariamente, por poetas sofisticados e intelectuais. A internet, não se pode esquecer, é o lugar do cidadão comum, mediano. Assim, os videopoemas, além de possuir características técnicas diferentes, também abrangem desde a arte abstrata até a expressão singela e ingênua com palavras, sons e imagens das pessoas comuns (teoricamente nãopoetas). $\mathrm{O}$ videopoema possui muito da ludicidade do poema tradicional com as palavras e do movimento icônico do videoclipe musical. Classificar uma performance virtual como um videopoema é, antes de tudo, uma operação arriscada, pois não existe o videopoema padrão. Penso que o olhar externo do leitor é que poderá definir um vídeo como videopoema, ou não.

Comecemos com um videopoema (?), ou um vídeo-animação, denominado " $\mathrm{Ru}$ bik's Cube Solve”, onde a palavra escrita é elemento secundário. O vídeo foi produzido e colocado no YouTube por um internauta identificado como Ron Y U, em janeiro de 2007, e construído através de um software chamado Gabbasoft. O autor não oculta a barra de ferramentas do software que utilizou e isto soa como metalinguagem, na performance digital. A canção de fundo, de cunho infantil, é "Tomorrow Hill”. O vídeo é uma exibição por imagem de computador de uma sessão de tentativas com um cubo mágico, com algumas frases dirigidas ao espectador. No final, o cubo explode, após uma contagem regressiva, e aparecem os créditos do trabalho. $\mathrm{O}$ próprio autor admite, em seu comentário na página do YouTube, que o seu vídeo é "nerd” (algo entre imbecil e debiloide). O vídeo está disponível em <http://www.youtube.com/watch?v=3il4Ap4KVwE\&feature=related $>$. Percebe-se que o autor não possui, aparentemente, grandes pretensóes artísticas com o seu vídeo, mas chama a atenção a harmonia entre a canção de fundo e as imagens do cubo, as cores e os movimentos, semelhantes a um desenho animado. Ainda assim, o vídeo é performático, pois o cubo exibe-se no centro da tela, capturando a atenção do espectador e ilustra, de modo livre, as palavras da canção de fundo, e esta, por sua vez, tem a ver com o cubo colorido que tenta se autocompletar inutilmente, até implodir.

Ainda no YouTube, encontramos o videopoema (neste caso mais verbal e, portanto, mais poemático) Overtype, (Superdigitado) de Nico Vassilakis, produzido em 
2007. Vassilakis disponibilizou diversos outros videopoemas no YouTube, quase todos construídos a partir de uma imagem abstrata e sons desconcertantes e dissonantes, em que não se reconhece facilmente as fontes que os produziram, a exemplo de Texture eTextorn e Flight of the Apostrophe. O vídeo é uma projeção em preto e branco, de cerca de 15 segundos, com uma visualização simbólica e abstrata, sugerindo o negativo de uma foto ou uma imagem radiográfica, onde textos e letras borradas vão sendo superpostas. O fundo musical é um som contínuo de timbre metálico, lembrando a passagem de uma sinfonia moderna, ouvindo-se ruídos ao fundo. É um videopoema curto, uma espécie de haikai digital. Neste caso, a palavra, em seu sentido tradicional, é obliterada, mas o poema, ainda assim, é um tanto verbal, pois parecem surgir sombras de letras. A abstração do som se integra à abstração da imagem. $\mathrm{O}$ poema não se revela como texto nem como imagem de fácil reconhecimento. É uma criação subjetiva, uma percepção visual criativa. Como todo videopoema, Overtype é um breve espetáculo para os olhos e ouvidos. Possui uma duração e uma forma de apresentação fílmicas, isto é, constitui-se em uma sequência de imagens e sons. Possui, portanto, características textuais, embora não se possa decodificar nenhum texto escrito. $\mathrm{O}$ trabalho mostra-se como linguagem e, por isso, possui a sua própria sintaxe. $\mathrm{O}$ videopoema está disponível em $<\underline{\text { http://www. }}$ youtube. $\mathrm{com} /$ watch? $\mathrm{v}=5 \mathrm{i} 3 \mathrm{ctHyl}$ UE\&feature=related $>$. Como todo vídeo do YouTube, este possui características hipertextuais interativas, pois o internauta pode deixar seus comentários na própria página, os quais influirão na recepção de outros internautas.

Algumas instituições renomadas como a BBC (British Broadcast Company) já investem na divulgação de videopoesia, como o site em conexão com o About.com. já tradicional na divulgação de textos literários on-line, cujo endereço é: <http://poetry. about.com/gi/dynamic/offsite.htm?zi=1/XJ/Ya\&sdn=poetry\&cdn=education\&tm=2 7\&gps=314 $211 \quad 1020 \quad 622 \& \mathrm{ff}=00 \& \mathrm{tt}=14 \& \mathrm{bt}=0 \& \mathrm{bts}=1 \& \mathrm{zu}=\mathrm{http} \% 3 \mathrm{~A} / / \mathrm{www} . \mathrm{bbc}$. co.uk/arts/poetry/ondisplay/>. O nome do site é Poetry on display (Poesia à mostra). Sendo um portal, o Poetry on display possui links para outros sites de videopoemas.

Um interessante videopoema deste site é Flight Comes Easily (O voo chega facilmente), texto de Khan Wong e design de Torisu Koshiro. A tela preta, com uma figura humana em vermelho e preto, é representada de modo desrealizado, ao fundo. $\mathrm{O}$ texto rola com letras brancas, com um ruído de vento na caverna. Embora o vídeo não seja tecnologicamente inovador, pois, como se percebe, poderia ter sido construído com simples recursos quase que inteiramente do Microsoft PowerPoint (o que não representa nenhum demérito), existe uma ligação entre texto e figura e dinamismo na performance.

O endereço para acessar o videopoema é:

<http://www.bbc.co.uk/arts/poetry/ondisplay/flight/flight.html>. 
$\mathrm{Na}$ avaliação de um videopoema, diversas variáveis que não fazem parte da leitura crítica do poema tradicional passam a interessar, como: o design da página, a interação texto-imagem-som (se houver), os efeitos especiais, a combinação de cores e tons, o nível de interatividade etc. A construção da poesia digital implica o conhecimento das ferramentas (softwares) que trabalham com imagem, texto, som e efeitos. Se o poeta conhece essas ferramentas e sabe manejá-las, o poema já nasce como um projeto integrado entre o texto poético e os recursos multimídia (aqui em um sentido muito mais amplo do que uma coluna de versos sobre uma folha de papel), com muito mais possibilidades de funcionar bem no meio eletrônico. A linguagem computadorizada e os efeitos utilizados já estarão influindo na concepção do texto verbal, desde o início. Se o poeta não estiver familiarizado com essas técnicas, o texto poético tradicional poderá ser transformado em videopoema pelo próprio autor, com uma consultoria sob sua orientação, ou por outrem. Neste último caso, o videopoema terá uma dupla autoria — do autor do texto e do criador do design em tela.

\section{Criando um videopoema simples}

Diversos programas podem ser usados para a construção de um videopoema. Dentre eles, o mais acessível é o PowerPoint, da Microsoft. Como exemplificação, descrevo a feitura do videopoema "O pássaro em si”, de minha autoria.

Aberto o PowerPoint, procede-se como na construção de uma apresentação comum. Cola-se o texto do poema dentro de um slide, insere-se uma foto temática como fundo e um fundo musical previamente escolhido é adicionado. Escolha a cor e os efeitos de animação visual e adicione à apresentação. Defina a velocidade e a forma de transição de slides, a qual, no videopoema em apreço, foi transição automática após 5 segundos. O videopoema "O pássaro em si” foi construído em três slides. Em seguida, com a ajuda do consultor em informática, Vagner Fonseca, o trabalho foi transformado em uma animação do programa Adobe Flash Player, com adição de música.

Para assistir ao videopoema (sim, "assistir" é mais apropriado do que "ler" um videopoema) "O pássaro em si”, acesse o site $<$ www.uneb.br/lucianolima $>$, e clique em videopoema "O pássaro em si". Certamente, assistir a um videopoema é uma forma de aprendizado mais eficiente do que ler uma exposição teórica e uma descrição detalhada sobre o mesmo. Boa recepção.

\section{$\operatorname{son}$}




\section{REFERENNCIAS}

DOMINGUES, Diana. Org. A arte no século XXI: a humanização das tecnologias. São Paulo: Editora UNESP, 2007.

DOMINGUES, Diana. Org. Arte e vida no século XXI: tecnologia, ciência e criatividade. São Paulo: Editora UNESP, 2003.

KROKER, Marilouise and KROKER, Arthur. Hacking the future: Stories for the Flesh-Eating 90s. Montreal: New World Perspectives, 1996.

LIMA, Luciano R. "Teoria e prática do hipertexto literário: análise da semiose do videopoema". In: LIMA, Luciano R. Literatura, crítica, teorias. Disponível em: <www.uneb.br/lucianolima >. Acesso em: fev. 2008.

WILSON, Stephen. Information Arts: Intersections of Art, Science, and Technology. London: The MIT Press, 2002.

\section{Resumo}

Este trabalho discute a natureza "performática" e intersemiótica do videopoema, ligada à noção de arte como performance, isto é, como um processo contínuo e não como um produto acabado, uma característica da contemporaneidade. Aspectos como virtualidade, criatividade, interatividade e imprevisibilidade na construção e recepçáo do videopoema são discutidos aqui. Como exemplificação, serão descritos e indicados videopoemas disponíveis na internet. Por último, são sugeridos alguns recursos técnicos de fácil acesso contidos no programa PowerPoint, relativos a efeitos sonoros e visuais, tanto fechados (acessáveis a partir de um repertório limitado dentro do próprio software) quanto abertos (inseridos a partir de qualquer música, filme ou vídeo já gravados), para a construção de videopoemas.

Palavras-chave: Videopoema; Performance; Interatividade; Criatividade.

\section{Abstract}

This work discusses "the performatic" nature and Intersemiotics of the videopoem, related to the notion of art as performance, that is, as a continuous process and not as a finished product, a characteristic of the contemporarity. Aspects such as potentiality, creativity, interactivity and unpredictability in the construction and reception of the video-poem are argued here. As examplification, described and available videopoems in the Internet will be indicated. Finally, some of easy access technical resources are suggested, contained in the PowerPoint software program, related to the sound and visual effects, both internal (you access it inside a limited repertoire of the proper software) and external (inserted from any music, film or video material already recorded), for the videopoem construction.

Key word: Videopoem; Performance; Interactivity; Creativity. 
LIMA, Luciano Rodrigues. O videopoema como performance: vista de literatura e diversidade cultural. Feira de Santana: UEFS, A. 13, $\mathrm{n}^{\mathrm{o}}$ 6, 2014, p 33-42.

Luciano Rodrigues Lima é licenciado em Letras com Inglês, tem Mestrado e Doutorado em Letras e Linguística pela UFBA. É professor Titular da UNEB e Professor Adjunto da UFBA. Atua como professor credenciado no Programa de Pós-Graduação em Letras e Linguística da UFBA, e no Programa de Pós-Graduação em Crítica Cultural da UNEB, Campus de Alagoinhas. É autor de dois livros de critica e estudos literários. 